\title{
“QUÉ VIVA LA MAMITA*!": TERRITORIALIDAD(ES), ESPESOR(ES) TEMPORAL(ES) Y RESISTENCIAS EN LAS PRÁCTICAS DE UN GRUPO DE DEVOTOS DEL CULTO A URKUPIÑA EN LA CIUDAD DE SALTA-ARGENTINA
}

\author{
“'Qué viva la mamita!”: territoriality (ies), temporal thickness (es) and resistances in \\ the practices of a group of devotees of the cult of Urkupiña in the city of Salta-Argentina
}

\author{
Daniela Nava Le Favi**
}

\section{Resumen}

La indagación se centra en el estudio de caso de un grupo de familias que se adjudican ser los dueños de una de las imágenes de la Virgen de Urkupiña más longevas de la ciudad de Salta- Argentina. La advocación mariana de origen boliviano se celebra, en el caso analizado, con novenas, procesiones y una fiesta lejos de los rituales que oficia la Iglesia Católica local para el culto en un doble sentido: por un lado, territorialmente y, por el otro, en cuanto a las modalidades de festejo. El trabajo parte de los estudios en comunicación/cultura en diálogo con aportes de la sociología y la antropología de las creencias para pensar que la experiencia analizada teje complejos procesos de territorialidad y de identificación, los cuales se construyen mediante negociaciones/apropiaciones de prácticas devocionarias de diversa procedencia cultural -como la andina en general, la boliviana y la salteña, en particular-donde el espesor temporal de las prácticas posibilita pensar la heterogeneidad cultural. La indagación pretende comprender el pasaje que se produce en un culto migrante que es apropiado/ disputado en el Noroeste Argentino.

\section{$<$ Territorialidades $><$ Espesores temporales $><$ Resistencias $><$ Heterogeneidad cultural $>$}

\begin{abstract}
The investigation focuses on the case study of a group of families who claim to be the owners of one of the oldest images to the Virgin of Urkupiñain the city of Salta - Argentina. The Marian invocation of Bolivian origin is celebrated, in the case analyzed, by novenas, processions and a party different from the worship rituals of the local Catholic Church. The differentiation process occurs in a double sense: spatially and in the celebration modalities. The work starts from studies in communication / culture in dialogue with contributions from sociology and the anthropology of beliefs to think that the experience analyzed weaves complex processes of territoriality and identification, which are constructed through negotiations / appropriations of devotional practices of Diverse cultural provenance - like the andean in general, the bolivian and the 'salteña', in particular - where the temporal thickness of the practices makes possible to think the cultural heterogeneity. The inquiry seeks to understand the passage that occurs in a migrant cult that is appropriate / disputed in the Argentine Northwest.
\end{abstract}

$$
<\text { Territorialities }><\text { Temporary thicknesses }><\text { Resistances }><\text { Cultural heterogeneity }>
$$

\footnotetext{
* La frase pertenece al discurso nativo y es pronunciada por los devotos en los rituales que constituyen la práctica mariana analizada.

** Licenciada en Ciencias de la Comunicación por la Universidad Nacional de Salta. Becaria Doctoral del CONICET. Doctoranda en Comunicación Social en la Facultad de Periodismo y Comunicación Social de la Universidad Nacional de La Plata. danielanavalefavi@gmail.com
} 
Nava Le Favi.“¡Qué viva la mamita!”: territorialidad(es), espesor(es) temporal(es) y resistencias en las prácticas...

Lía $^{1}$ tiene más de 70 años y se prepara para bailar junto a los caporales ${ }^{2}$ en la procesión a la "Mamita", nominación común que usan los devotos 3 para referirse al culto de Urkupiña en Salta ${ }^{4}$. De hecho, el apelativo para identificar esta forma de religiosidad migrante - que ha sido asimilada por numerosas familias salteñas- contribuye a solidificar el discurso devocional asociado a la representación de una posición de "hijos" en relación a la divinidad y de "hermandad" al interior de las contactos interpersonales que se establecen entre los creyentes durante las prácticas rituales que se realizan en honor a la Virgen.

Para los medios de la prensa gráfica salteña, la configuración del culto adquiere connotaciones negativas por tratarse de una "invasión cultural" de los bolivianos en el territorio "salteño", haciendo referencia al origen histórico del culto y obliterando que la práctica suma devotos a una velocidad casi geométrica, dado el marcado proceso de territorialización en la ciudad: son cada vez más numerosos los autos y negocios del macrocentro que tienen un altar a la devoción o inscripciones de agradecimiento a la Virgen ${ }^{6}$.

Lía junto a su hijo Pedro, forman parte de un grupo de familias devotas que se adjudican ser los ingresantes del culto en la Capital: los rituales son practicados en la intersección del espacio público/privado y por fuera de aquello que dispone la Iglesia local, produciendo espacios y tiempos autónomos al dogma para la realización del culto. En este sentido, se constituye en una experiencia fértil para abordar las resistencias y el lugar del poder en los modos de decir, de hacer y habitar la ciudad.

1 Todos los nombres de los informantes fueron modificados para preservar el anonimato de los mismos.

2 Los caporales al igual que los tinkus, las morenadas y las diabladas son grupos de bailes que se diferencian entre sí por la vestimenta colorida de los bailarines y los sombreros de las bailarinas. Los mismos conforman la fachada étnica de la festividad (Rivero Sierra, 2008)

3 El trabajo usa indistintamente las categorías de devotos, creyentes, fieles. Sin embargo, las distinciones serán rigurosas en el momento del análisis del discurso nativo, es decir, aquellas que Bourdieu (2013) denominaría "las categorías de la práctica".

4 Salta es una ciudad, un municipio y la capital de la provincia de Salta, República Argentina que tiene una población de 535303 habitantes, siendo la ciudad más poblada de la provincia y la séptima del país. Información obtenida de: http://estadisticas.salta.gov.ar/web/

5 La forma de caracterización del culto como una "invasión cultural" se encuentra en una nota publicada por el Diario Intransigente el 3 de diciembre del año 2010. En relación al tratamiento que hace la prensa salteña del culto, existen algunas indagaciones que muestran cómo se construyen representaciones estigmatizantes alrededor de los devotos de Urkupiña: los medios reproducen narrativas que los postulan como "invasores" del territorio local por ser "bolivianos", obliterando la gran asimilación que hay también- por parte de familias salteñas. Las formas de nominarlos reproducen estructuras coloniales que posicionan e identifican como out-siders a los devotos de la Virgen de Urkupiña al punto tal de subalternizarlos comparándolos con rasgos de animalidad. Esa estigmatización no sólo se produce por una identificación basada en la nacionalidad sino que, además, por ser una advocación que se encuentra en la frontera de lo estipulado por el dogma católico en Salta, religión hegemónica en las matrices culturales de la sociedad local (Nava Le Favi, 2015 y 2016) Esto también da cuenta de la inscripción del discurso religioso en el mediático (Cebrelli, 2010; Nava Le Favi, 2013).

6 En cuanto al proceso de territorialización de la devoción en la ciudad podría pensarse que se presentan estrategias por parte de los devotos que exhiben en sus comercios la imagen de la Virgen, legitimando con sus altares o con los nombres de sus negocios, el culto. Allí, la manera en la que comerciantes muestran su devoción marca una inscripción en el espacio entramado en un proceso de visibilización que excede este trabajo, pero donde se tensionan formas de concebir lo "público" en relación a prácticas religiosas. 


\section{Puntos de partida: abordajes y especificaciones del caso}

El análisis se inscribe en la línea de los estudios latinoamericanos que piensan la relación entre comunicación-cultura (Martín Barbero, 2002; Ford, 1985; Reguillo, 2007 y 2008), en tanto se retoman las perspectivas de la socio-semiótica (Verón, 1987; Angenot, 1998), la teoría de las representaciones sociales (Cebrelli y Arancibia, 2005, 2010 y 2011; Rodríguez, 2008 y 2011), de las identidades (Brubaker y Cooper, 2002; Hall,2003), enfoques sobre territorio (Segato,1999, 2007; Cebrelli y Arancibia, 2010) aportes de estudios andinos (Canepa Koch, 1998; Gisbert,2010; Pimentel, 2009; Irarrázaval, 1994), de la historia cultural en relación a devociones marianas (Chaile, 2010 y Fogelman, 2005) aportes sobre religiosidad de la sociología y la antropología (Semán, 2000; Turner, 1969) y perspectivas poscoloniales (Cornejo Polar, 1994).

La indagación se centra en un estudio de caso que implica reflexionar sobre las prácticas de un grupo de familias que se adjudican ser los dueños de una de las imágenes más longevas de la ciudad y, por lo mismo, ser el grupo que "ingresó"7 la devoción en el territorio local. La advocación mariana de origen boliviano se celebra, en la experiencia analizada, con novenas, procesiones y una fiesta que se realiza en una finca a más de 20 kilómetros de la Capital, lejos de los rituales que oficia la Iglesia Católica local para el culto. En este sentido, el trabajo explora las tensiones entre los rituales que practican los devotos y la institución en clave de pensar cómo se va configurando la apropiación ${ }^{8}$ de los espacios públicos/ privados por parte de los actores sociales, centrándose especialmente en la fiesta, momento denominado por los creyentes como el "cumpleaños de la Mamita".

El caso pone en evidencia complejos procesos de territorialidad y de identificación que se construyen mediante negociaciones/apropiaciones de prácticas devocionarias de diversa procedencia cultural. El trabajo parte de la premisa que la devoción pone en diálogo sistemas de representaciones-como la cultura andina en general, la boliviana y la salteña, en particular-donde el espesor temporal de las prácticas posibilita pensar la heterogeneidad cultural que se teje en un culto migrante y apropiado en el Noroeste Argentino.

El grupo de personas en el que se centra el análisis participa y construye otro tipo de territorialidad (Foucault, 1983, 1988 y 2004; Segato, 2008 y 2007; Arancibia, 2009) que atraviesa un lugar público no legitimado por el Arzobispado. Además, se inscribe en un espacio privado y doméstico que implica una forma particular de apropiación/asimilación por parte de los actores sociales, permitiendo comprender a los

${ }^{7}$ El entrecomillado se debe a que la apreciación corresponde a la percepción de las familias. De acuerdo a las entrevistas realizadas entre los años 2014 y 2016, el grupo afirma ser quien ha iniciado la devoción en la ciudad de Salta.

8 La práctica al culto de la Virgen de Urkupiña es un proceso mariano complejo y dinámico y, más aún, si se considera que hay territorialización del culto a nivel nacional y local que impide realizar afirmaciones cerradas por las múltiples variaciones y apropiaciones de la advocación, característica fundamental del culto por cuanto depende de la forma en la que el devoto establezca su relación con la divinidad. Al respecto, una tesis de producción fotográfica mapea las múltiples apropiaciones que se realizan de la advocación en la ciudad de Salta poniendo énfasis en el modo en que los creyentes visten de múltiples formas (y significancia) al bulto de la "Mamita" (Juárez, 2015). 
Nava Le Favi.“¡Qué viva la mamita!”: territorialidad(es), espesor(es) temporal(es) y resistencias en las prácticas...

devotos como individuos capaces de elegir el curso de sus acciones (Carrozzi y Frigerio, 1994). El trabajo implica una pregunta por lo popular, el lugar de las resistencias y el poder (De Certeau, 1996, Bajtin: 1998) y, en particular, por cómo se configura esta experiencia de la religiosidad popular (Semán, 2000) teniendo en cuenta que ante el creciente proceso de territorialización (Deleuze y Guattari,1997) de la devoción de Urkupiña en la ciudad, hay un proceso de "centralización" por parte de la Institución Católica salteña para legitimar espacios de tránsito $\mathrm{y}$, de esa manera, disciplinar los cuerpos de los devotos. El abordaje de las tensiones y disputas que se tejen en esta experiencia de religiosidad mariana tiene como método un análisis del discurso de base socio-semiótica (Verón, 1987 y Angenot, 1998) que permite leer los enunciados de los fieles y algunas notas periodísticas de diarios provinciales que corresponden al periodo 2010-2016. Además, se parte de una mirada etnográfica (Guber, 2001) sobre las prácticas, la cual retoma información obtenida de observaciones participantes (Callejo Gallego, 2002) y entrevistas en profundidad (Petracci, 2004) a diez miembros de las familias como, también, más de veinte testimonios de diversos grupos devotos que posibilitan contextualizar la práctica ritual de Urkupiña en Salta. El trabajo de campo ha implicado considerar principalmente los tiempos y espacios que transitan las familias del caso a analizar, el cual comprende un lapso que comienza desde el 6 de agosto con el rezo de la novena en la casa de los Flores en el Barrio Miguel Ortiz, las procesiones el día 14 de agosto en el mismo barrio, las misas de bendición a las imágenes en la Iglesia Santa Rita de Cassia y la fiesta en La Caldera- Salta el 15 de agosto (día de la Virgen) entre los años 2014 y 2016.

La presente indagación parte de una conceptualización sobre el territorio, un constructo atravesado por representaciones sociales e identificaciones que albergan preguntas como quién soy, dónde estoy, a qué nosotros pertenezco, dónde me localizo y qué lugar ocupo, cómo me relaciono con él y qué historias me entraman a él (Arancibia, 2009). La territorialidad es una experiencia particular, histórica y culturalmente definida de ese territorio (Foucault, 1983 y 2004). El caso analizado implica una territorialidad atravesada por rituales, es decir, artefactos comunicativos que inscriben ese espacio, lo consagran, lo sacralizan (Segato, 2008) y que se constituyen como espacios liminares que permiten pensar - en algún punto- el cambio y los cuestionamientos al orden (Turner, 1969).

Las prácticas de este grupo se encuentran en el cruce entre el espacio privado/ público construyendo una territorialidad móvil (Segato, 2007 y 2008) marcada por las apropiaciones, usos, símbolos que están al "margen" de lo establecido por la Institución Católica. De allí que este trabajo propone pensar el concepto de territorialidad para marcar no sólo lo "móvil" de ese espacio sino, además, cómo se tensiona lo legítimo, el poder y las resistencias a lo "establecido", los modos en que los cuerpos viven y atraviesan esos lugares con prácticas de diversos espesores temporales y cargados de múltiples identificaciones.

La categoría de espesor tempora ${ }^{9}$ de las prácticas y los discursos habilita a reflexionar sobre cómo a una determinada representación social se le van adosando

9 La categoría de espesor temporal (Cebrelli y Arancibia, 2010; Cebrelli, 2011) habilita a comprender no 
modos de significar, de hacer, de percibir y de decir complejizando la estructuración de dichas representaciones. Este proceso es propio de las formaciones discursivas y de los modos de circulación que tienen (Cebrelli y Arancibia, 2005). De esta manera, la prescripción pragmática de una representación responde a los aspectos que en ese momento socio-histórico se validan como significativos "claro está que ese modo rara vez es una invención del actor social sino que ya estaba en el campo validado por otros agentes que abonaron - reproducción mediante- la validez de esa forma de hacer y de decir" (Cebrelli-Arancibia, 2005: 121-142). La práctica de este grupo de familias está inscripta en diversos espesores temporales -como lo "andino"- remitiendo a un proceso de heterogeneidad cultural que posibilita pensar, también, las tensiones/negociaciones con el dogma católico.

El trabajo se estructura en dos líneas de análisis: en la primera se intenta reconstruir brevemente la historia de los festejos de este grupo de familias, cómo se presenta el paso de un culto privado a una celebración que no incluye el tránsito de la imagen por los lugares públicos marcados por la Iglesia Católica Salteña, la manera en que la institución refuerza una acción estratégica mediante diversos medios para

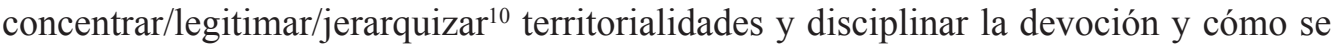
configura la práctica de esta familia frente a los intentos de centralización.

Un segundo nivel de análisis, intenta indagar el espacio "privado" en el que se inscribe esta territorialidad construida por los devotos. Allí, interesa explorar algunos elementos del momento denominado por los devotos como el "cumpleaños a la Mamita", donde los relatos y las agencias posibilitan pensar la heterogeneidad cultural en términos de espesor temporal de las representaciones y prácticas inscriptas en lógicas cercanas al carnaval bajtiniano y con ciertos procesos culturales referidos a lo "andino".

Las prácticas y los relatos de Lía, Pedro y el grupo de familias permiten comprender los sentidos que le otorgan a la advocación, lo cual implica una distancia a lo estipulado por la Iglesia local en un doble sentido: por un lado, territorialmente al realizar las misas y procesiones en la parroquia Santa Rita de Cassia y no en la Iglesia Nuestra Señora del Pilar ${ }^{11}$ como lo ha dispuesto el Arzobispo Mario Antonio Cargnello ${ }^{12}$.

sólo las múltiples temporalidades de una práctica, sino que evita reproducir una mirada esencialista y ajena al contexto migratorio en el que se enmarca la devoción, característica de algunas indagaciones que tienden a pensar que ciertos grupos y sus culturas son inmodificables (Herrera, 2000).

${ }^{10}$ Podría pensarse que el proceso de centralización que impone la Iglesia al culto habla, al mismo tiempo, de una jerarquización de los espacios en relación a otras devociones consideradas tradicionales en la ciudad de Salta. Al respecto, un trabajo indaga la comparación entre el culto del Milagro (en el cual participa toda la Arquidiócesis de Salta) y Urkupiña en la ciudad: la contrastación permite pensar que la disputa territorial se traduce en la forma en la que los rituales del canon católico -practicados por la primera devoción mencionada- pueden realizarse en los centros (como la plaza principal) y cómo la devoción boliviana se la excluye a otros espacios lejanos (geográficamente) a esos centros de visibilidad y poder en la capital salteña (Nava Le Favi, 2016).

${ }^{11}$ El trabajo usa indistintamente la nominación "Iglesia Nuestra Señora del Pilar" e "Iglesia del Pilar" para referirse al mismo templo. La segunda hace referencia a una designación más breve del lugar que circula tanto en la esfera de la institución, en medios de la prensa gráfica y en el discurso de los devotos.

${ }^{12}$ En un comunicado del Arzobispado de Salta titulado "La devoción de la Virgen de Urkupiña y Salta" señala en el punto $\mathrm{N}^{\circ} 2$ que la Arquidiócesis de Salta confió a la parroquia de Nuestra Señora del Pilar 
Nava Le Favi.“¡Qué viva la mamita!”: territorialidad(es), espesor(es) temporal(es) y resistencias en las prácticas...

Por otra parte, las modalidades de festejo también incluyen prácticas disruptivas al canon católico local ${ }^{13}$, lo que va confluyendo en la construcción de ritualidades que sacralizan el espacio desde las agencias de los devotos.

De esta manera, el trabajo intenta contribuir a una primera aproximación sobre cómo se da el pasaje de una práctica de un culto boliviano ${ }^{14}$ a otra que es apropiada/ disputada/negociada por el noroeste argentino, en tanto ese proceso significa conflicto y, al mismo tiempo, ejercicio de la defensa de una territorialidad que se construye alrededor de un ritual mariano, en la cual hay prácticas, narrativas, saberes, pasiones, identificaciones y cuerpos que lo viven, lo transitan y lo significan (Arancibia, 2009; Segato, 2007).

\section{Tensiones en el espacio público: la posición de la Iglesia Católica local y el municipio en relación al culto}

Desde fines del siglo pasado, en el catolicismo se desplegó un reconocimiento fundamental a la imagen mariana, dado que permitía desplegar una modalidad litúrgica superadora de la rigidez doctrinaria, cuya consecuencia fue la creciente expansión de la devoción y su instalación en el imaginario de los creyentes (Ameigeiras, 2012 y Fogelman, 2005). En ese contexto, cabe destacar que el origen mítico de la Virgen de Urkupiña no se aparta de las narrativas marianas en la cual la persona que en principio entra en contacto con la divinidad proviene de sectores no privilegiados (Chaile, 2010 y Fogelman, 2005): según la historia oficial ${ }^{15}$, a fines del siglo XVII en Cochabamba -Bolivia, a una niña perteneciente a una familia de campesinos se le aparece una señora con un niño en sus brazos y con la cual comienza a sostener largas conversaciones

el servicio eclesial a los devotos del culto. Allí, podría pensarse cómo se intenta centralizar y anclar la advocación en un solo lugar. El documento se encuentra disponible en: http://www.arquidiocesissalta. org.ar/admin/documentos/1383670506_La $\% 20$ devoci $\% \mathrm{C} 3 \% 83 \% \mathrm{C} 2 \% \mathrm{~B} 3 \mathrm{n} \% 20 \mathrm{a} \% 201 \mathrm{a} \% 20$ Virgen $\% 20$ de $\% 20$ Urkupi $\%$ C3\%83\%C2\%B1a\%20y\%20Salta\%20(1).pdf

${ }^{13}$ La imagen original de la Virgen de Urkupiña fue llevada desde Quillaicollo- Bolivia a Salta en el año 2014. En el centro de Convenciones de la Ciudad se organizó la entrada folclórica donde cientos de fieles bailaron caporales, morenadas, tinkus, diabladas para la Virgen. El Arzobispado formaba parte de la organización y se impuso la condición que no podría ingresarse al predio con pirotecnia ni bebidas alcohólicas (Diario El Intransigente, 23 de Mayo de 2014), elementos que -como se ahondará más adelante-constituyen la práctica de este grupo de familias.

${ }^{14} \mathrm{Si}$ bien no es objeto de este trabajo ahondar en una comparación exhaustiva, cabe destacar que el culto en Cochabamba - Bolivia implica una exhibición de las jerarquías eclesiásticas y políticas durante la procesión que se efectúa en el centro de la cuidad, en tanto la celebración de rituales se realiza durante la mayor parte del mes de agosto (Giorgis, 2000). En el caso de Salta, las ritualidades se practican por familias devotas y la presencia eclesiástica se reduce a los curas de parroquias barriales donde son llevadas las imágenes para la bendición, procesión o misas. Además, la práctica no sólo presenta rasgos de dispersión espacial - más allá de los intentos de centralización del culto por parte del Arzobispado local- sino, también, temporal: desde el mes de agosto hasta diciembre existen muestras de veneración a Urkupiña por parte de los creyentes, las cuales son discontinuas en tanto dependen de la creatividad de los devotos (algunos alquilan salones, otros lo realizan en su casa, por ejemplo) y de la capacidad económica (hay quienes llevan a misa a sus imágenes el día 15 de agosto, día de la Virgen, y festejan en septiembre, cuando han juntado el dinero para comprar los elementos que utilizarán en la fiesta).

${ }^{15}$ Hay diferentes páginas dedicadas a la Virgen de Urkupiña, las cuales remarcan este origen mítico. Véase: http://www.urcupina.com/ 
en quechua. Después de reiteradas visitas, la pastora le cuenta a sus padres y éstos al sacerdote doctrinero del lugar. La virgen "sube" a una de las cimas del Cerro, mientras la niña gritaba "Jaqaypiñaorqopiña, orqopiña", que significa "ya está en el cerro"(orqo=cerro, piña=ya está), de ahí el nombre castellanizado de Urkupiña.

La advocación de Urkupiña en el noroeste argentino tiene la particularidad de ser un culto asimilado por familias salteñas, lo cual se constituye como una característica distintiva de otras experiencias analizadas en el país donde se configura más como un culto migrante ${ }^{16}$. Esta distinción puede encontrar algunas respuestas en términos históricos hacia finales del siglo XVIII y principios del XIX momento en el cual la región estaba más ligada a la economía altoperuana por la minería, lo que posibilitó la formación de una parte importante de la clase dominante salteña (Madrazo, 1981). La poca actividad económica en el noroeste hacia fines del siglo XIX postergó, también, la migración europea que ya estaba cambiando la fisonomía de la región pampeana.

En el noroeste prevalecía un paisaje andino e indígena que iba en contracorriente del mito de la Argentina blanca y europea (Yudi, 2015). En el siglo XX, la imagen de Salta comenzó a construirse por salteños vinculados a las letras (Juan Carlos Dávalos fue uno de los exponentes) que empezaron a tensionar el binomio tradiciónmodernidad. De esta manera, se pensaba a Salta como "una ciudad de fuertes tradiciones hispanos-indígenas, con una estructura social segmentada en la oligarquía criolla que se vanagloriaba de su origen patricio y de su linaje aristocrático-español" (Álvarez Leguizamón, 2010: 12). En este periodo se consolida una imagen de "salteñidad" asociada a las tradiciones católicas para buscar un lugar diferencial en el imaginario nacional sedimentado en el modelo agro-exportador que ya había dejado al noroeste en un lugar residual "la defensa de la Iglesia Salteña y los grupos tradicionalistas harían valer con mayor fuerza sus atributos morales e históricos para diferenciarse de aquellas provincias que la superaban por su progreso" (Flores Klarik, 2010). Este aspecto, arroja algunas respuestas pre-liminares sobre la posición de la Iglesia Católica en la actualidad y cómo se configura en un lugar hegemónico de enunciación sobre la construcción de la identidad local (Nava Le Favi, 2013)

Los múltiples contactos entre el noroeste argentino y la zona andina en los períodos pre y poscolonial, se complejizaron con procesos de migración en los incipientes estados nacionales. La mayor afluencia de inmigrantes bolivianos hacia

\footnotetext{
${ }^{16}$ A nivel nacional, se han realizado trabajos que dan cuenta de las particularidades que adquiere el culto de Urkupiña en diferentes ciudades. Sin pretender realizar un análisis exhaustivo de los estudios en relación a la problemática, se puede pensar en el caso de Marta Giorgis (2000) que indaga la festividad en una colectividad boliviana del gran Córdoba o Barelli (2011) quien también problematiza la construcción de identidades en migrantes bolivianos en relación al culto. Ambas propuestas, no sólo dan cuenta de las múltiples re-apropiaciones que se hacen del culto y son un antecedente para pensar particularmente esta advocación en otros contextos en Argentina, sino que tienen la especificidad de marcar que aún esta devoción es una práctica que se festeja entre "bolivianos". En Jujuy como lo han dado cuenta trabajos de Guzmán (2009) hay ciertas similitudes con el caso salteño, sin embargo la festividad es más prolongada en la ciudad de Salta. En relación a trabajos que ponen el acento en la relación entre fiesta y los estudios migratorios Herrera (2000) realiza un recorrido atento por éstos trabajos, analizando algunos que problematizan cultos religiosos y marianos (Bonaparte, 2005; Giorgis; 2004; Serafino: 2010, Passarelli y Gimenez: 2015).
} 
Nava Le Favi.“¡Qué viva la mamita!”: territorialidad(es), espesor(es) temporal(es) y resistencias en las prácticas...

el noroeste argentino se registra en la década del '60. Allí, intervinieron dos factores internos relacionados al contexto que atravesaba el país vecino: se presentó una baja capacidad de retención de mano de obra campesina más bajos niveles de producción que conllevaron a una migración a países limítrofes (Marshall y Orlansky, 1980). El ' 85 también marca un antes y después en la historia de inmigrantes bolivianos, ya que debido a la aplicación de políticas neoliberales -como la privatización de las minas- con el consecuente deterioro de la vida campesina boliviana impacta en flujos migratorios internos y externos (Domenech y Magliano, 2007).

Entre los periodos de inmigración boliviana brevemente mencionados, se ubica la historia del caso a analizar, cuya esclava ${ }^{17}$ de la primera imagen de la Virgen se llamaba Elba, mujer jujeña, casada con un hombre boliviano, la cual curaba y realizaba milagros con el bulto de la Virgen. Según el relato de las familias, la estampa de Urkupiña se la regala una comadre de la difunta Elba, Silvia, hace más de treinta y seis años. Actualmente, el grupo organizador de la fiesta tiene un altar en la casa de los Flores ubicado en el Barrio Miguel Ortiz ${ }^{18}$, donde alberga a más de cincuenta imágenes de Urkupiña, todas "hijas" dirá Lía, del bulto de Elba, marcando con su relato la reproducción del culto.

El grupo de familias organizadoras se encuentra conformado por los cinco hijos de Elba que constituyen la familia Flores, todos nacidos en la ciudad de Salta. La segunda familia es la comadre de Elba, Lía, quien participa junto a su hijo Pedro y conforman la familia Camacho. Ambos nacieron en Sucre, Bolivia. Finalmente el compadre de Elba, Julio, junto a su mujer, sus dos hijos y nietos forman la tercera familia organizadora, los López. Julio y su mujer nacieron en La Paz, mientras que hijos y nietos nacieron en Salta. Según Pedro, en la fiesta "son más salteños que bolivianos, el culto ya está muy instalado aquí", ${ }^{19}$ resaltando con su frase no sólo la asimilación del culto, sino como los cuerpos que transitan ese territorio están inscriptos en diversas identificaciones.

De acuerdo al relato del grupo de familias, el culto tiene una expansión entre los vecinos del barrio y años más tarde en la ciudad, hacia mediados de la década del '90. Esta expansión coincide con una etapa histórico-política del país ligada a procesos neoliberales que conllevaron a una desestructuración social que devino en pérdidas de identidad y falta de horizonte social. En este contexto, se dan una serie de emergencias religiosas donde se mezclan los símbolos, los fetiches, los rituales, las creencias oficiales y no oficiales ayudando a re-construir la identidad y en muchos casos la solidaridad,

\footnotetext{
${ }^{17} \mathrm{La}$ "esclava" es el término nativo de la práctica que designa a quienes poseen y deben encargarse de cuidar la imagen (ya sea con flores, limpiar el altar, cambiar vestidos y joyas). Algunos esclavos tienen más de una imagen a su cargo y, en las percepciones de los creyentes, no es bien visto comprar el bulto dado que es la Virgen quien elige a su esclavo. De esta manera, muchos esperan que les sean regaladas o que por promesa un esclavo pase la imagen a otra persona donde media una relación familiar o de parentesco ritual como ser comadre, compadre, madrina, ahijado/as (Guzmán, 2009).

${ }^{18}$ De acuerdo a la Dirección Estadística de Salta y en base al último censo poblacional del año 2010, el barrio presenta un $70 \%$ de habitantes bolivianos e hijos de bolivianos, siendo uno de los sectores con mayor residencia de inmigrantes del país homónimo.

${ }^{19}$ Frase extraída de una entrevista realizada a Pedro el día 15 de agosto del año 2015 durante la fiesta en La Caldera- Salta.
} 
como base del tejido social (Dri, 2003). De acuerdo a indagaciones recientes, la Virgen de Urkupiña en Jujuy tiene este período de origen y visibilización (Guzmán, 2009) mientras que en la ciudad de Salta y de acuerdo al relato de las familias, coincide más con una etapa de expansión.

Entre el año 2010 y 2011 se presenta una creciente visibilización en los medios de comunicación ${ }^{20}$ locales por la fiesta de la Virgen de Urkupiña que se realizaban en las calles de diferentes barrios de la ciudad: los esclavos y devotos llevaban la imagen en autos o colectivos hasta la Iglesia de los barrios en medio de música, papel picado y danzas de caporales, pedían la bendición para la Virgen y regresaban a la casa de los dueños de las imágenes de la misma manera. Allí, hay un punto de inflexión ${ }^{21}$ : los medios locales comienzan a hablar de "ruidos molestos" e incluso concejales plantearon la posibilidad de sancionar una ordenanza que prohíba la realización del culto porque era ruidoso ${ }^{22}$. En lo no dicho, la devoción estaba en un proceso de territorialización del espacio público consagrado, tradicionalmente, a festividades como el culto del Milagro (Nava Le Favi, 2013 y 2016).

En el año 2013, el Arzobispo de Salta se pronuncia a favor de la devoción de Urkupiña y anuncia la llegada de la imagen original de Bolivia a la ciudad para el siguiente año. Posteriormente a ese evento, comenzó a centralizarse la novena y procesión en la Iglesia del Pilar, lugar donde se encuentra la réplica exacta del bulto de Urkupiña. A principios del año 2015, la institución emite un comunicado ${ }^{23}$ invitando a los devotos a hacer sus donaciones para construir un santuario cerca de uno de los cerros que rodea la ciudad y con ello, establecer una territorialidad "legítima" para realizar el culto por parte de la Institución ${ }^{24}$ e, implícitamente, controlar la creciente expansión que tiene el culto en la ciudad ${ }^{25}$.

\footnotetext{
${ }^{20} \mathrm{Al}$ respecto, hay indagaciones que van mapeando enunciados de la prensa gráfica local durante el periodo citado donde se puede observar cómo el culto se comienza a visibilizar desde el estigma, es decir, con connotaciones negativas las cuales sedimentan la imagen de un culto "ruidoso" que "invade" el espacio público (Nava Le Favi, 2016).

${ }^{21}$ Se podría leer en esa inflexión la capacidad de inculturación (Irarrázaval, 1994) de la Iglesia y de los medios de la prensa gráfica en cuyos enunciados existe una inscripción del discurso católico (Nava Le Favi, 2013; Cebrelli, 2010). Este proceso puede encontrarse en la necesidad de modificar el comportamiento que adoptaban los devotos del culto porque -en lo no dicho- lo "ruidoso" o lo "molesto" también da cuenta de una disputa por quién tiene el monopolio religioso.

${ }^{22}$ Fueron diversos los intentos de ediles de sancionar ordenanzas prohibiendo la realización del culto de Urkupiña por los ruidos molestos como el concejal Aroldo Tonini, en el año 2012. Diputados provinciales, como Ricardo Alonso se manifestaron en contra del culto con fuertes posiciones xenófobas, provocando que el Consulado Boliviano se pronunciara en contra de estos dichos: http://www.fmcapitalsalta. com/noticias/1612/alonso-exprese-la-preocupacion-de-los-vecinos-por.html. Sin embargo, luego del pronunciamiento a favor del culto por parte de la Iglesia, el Concejo Deliberante declara de interés cultural la visita de la Virgen a Salta en el año 2014 http://www.cdsalta.gob.ar/sites/default/files/user/ upload/VERS-TAQ-14Mayo2014-PDF.pdf

${ }^{23}$ El comunicado se encuentra disponible en: http://www.arquidiocesissalta.org.ar

${ }^{24}$ Este dato es producto de observaciones participantes que se realizan desde el año 2013 en diversos barrios de la capital salteña. Hasta mediados del 2013 y principios del 2014 podría pensarse que el culto de Urkupiña es "disperso" en cuanto espacio legitimado para realizar la devoción, ya que dependía del lugar donde residían o querían festejar el culto sus promesantes.

${ }^{25}$ El Arzobispo de Salta, Mario Antonio Cargnello, ha dispuesto que la novena y la procesión se realicen
} 
Nava Le Favi.“¡Qué viva la mamita!”: territorialidad(es), espesor(es) temporal(es) y resistencias en las prácticas...

El concepto de estrategia, tal como lo piensa De Certeau (1996) permite comprender la posición de la institución en relación a la devoción, cómo intenta nuclear la práctica en un espacio producido/demarcado desde la visión católica, regulando los usos y significaciones que hacen los devotos del culto. Así, la prohibición del alcohol o pirotecnia en la Iglesia del Pilar muestra cómo se ha tratado de imponer una forma y un espacio para los festejos que dista de la manera en la que los devotos "salteños" y "bolivianos" viven el cumpleaños a la "Mamita".

Podría sostenerse que el grupo de familias Flores- Camacho- López marcan tácticas populares al no participar de los espacios que ha legitimado la Iglesia Católica, en tanto la familia sigue manteniendo la "fiesta" de la Virgen en el ámbito privado. Este aspecto sobre cómo se tensiona lo privado/lo público debe comprenderse en el seno de las disputas que instaló el modernismo: se establece la masculinidad en el espacio público y lo femenino en el espacio doméstico (González Sthepan, 1995). Además, habilita pensar la manera en que los rituales católicos son permitidos en ese espacio público en la ciudad de Salta, ${ }^{26}$ mientras aquellos que están fuera del canon deben restringirse al ámbito privado reproduciendo la dicotomía civilización/ barbarie (González Sthepan, 1995). En este sentido, Bourdieu (2013) piensa que la puesta en escena de ceremonias colectivas no sólo ordena los pensamientos y sentimientos del grupo que participa, sino que también implica una eficacia simbólica sobre los cuerpos y las creencias en estrecha relación con los espacios que se transitan. Las procesiones son realizadas en lugares públicos/ masculinizados (González Sthepan, 1995) con fuegos de artificios, bailes, música, configurando una práctica que no se encuadra en el marco de lo regulado por el dogma católico y produciendo una tensión/disputa, al punto tal de necesitar excluir la devoción de los centros de visibilidad y poder. Si el ámbito privado posibilita ciertas flexibilidades y lo público es el espacio de la norma, de la censura, es en esta intersección de espacios y de actores que se construye esta territorialidad vivida y habitada por cuerpos que practican una fiesta a "la Mamita" lejos de lo legitimado por la Iglesia local.

\section{El cumpleaños a la "Mamita": lo "andino" y la heterogeneidad cultural}

Son las ocho de la mañana del día 15 de agosto y las familias ya están en la finca en La Caldera donde realizarán la fiesta. Un cartel con los colores de la bandera

en la Iglesia del Pilar, además de prohibir la utilización de bebidas alcohólicas para "chayar", ritual que tiene un espesor temporal andino y que se efectúa en otras fiestas a la Pachamama. La situación sobre la prohibición del uso de elementos significativos en el culto es una situación común en otras experiencias a nivel país, como las analizadas por Pasarrelli y Gimenez (2015) en el caso de La Plata. Sin embargo, allí la tensión con la Iglesia local presenta otros matices, dado que la institución no puede rechazar abiertamente las prácticas del culto por miedo a perder sus influencias en el barrio donde están insertas.

${ }^{26} \mathrm{Al}$ respecto, hay un trabajo que indaga cómo el culto del Milagro en Salta cuenta con la legitimación de la Iglesia y del municipio, al punto tal que no sólo los días de la festividad están declarados como feriados sino que -además- no puede realizarse ningún otro evento cultural (Nava Le Favi, 2013). El culto del Milagro, forma parte del catolicismo popular y está sedimentado en las representaciones de los medios- incluso de los gobiernos de turno- como parte de la "salteñidad", mientras que el culto de Urkupiña vendría a disputar los espacios (incluso el público) históricamente consagrado a ésta devoción colonial (Nava Le Favi, 2016 y 2013). 
salteña, boliviana y argentina dice "Feliz cumpleaños, Mamita". La imagen de la Virgen de Elba (que unas horas antes recibió la bendición en la Iglesia Santa Rita de Cassia) ingresa primero al predio en medio de aplausos, música de caporales y fuegos de artificios. Seguidamente, entran las otras imágenes "hijas" de la Virgen y se ubican en una enorme mesa en la entrada. A los pies de los bultos, las familias van dejando tortas y también velas. Cada uno de los participantes se prepara para compartir una jornada completa en la finca. Hay abundancia: mucha comida, más de cien cajones de cerveza para chayar las piedras y alacitas ${ }^{27}$ todos elementos donados por los creyentes. Allí, las personas ríen y "festejan" el cumpleaños. Lía dirá emocionada que la alegría es porque la Mamita es "cumplidora"28 otorgándole al culto un estatus de efectividad en la relación divinidad-creyentes.

Los devotos se ubican por diversos lugares, los espacios no están disciplinados/ demarcados, los niños corren, juegan, las familias conversan, algunas tocan la guitarra, cantan. Los Camacho están cerca de la gruta de la Virgen, allí Pedro maneja los micrófonos y la música. Sin embargo, todos pueden utilizar los equipos y hacer pedidos $^{29}$. Antes del almuerzo, Lía y la familia López lideran una peregrinación hacia la cima del cerro, donde bajan las piedras que entre todos los participantes chayaran con cerveza y romperán para -de acuerdo al tamaño- saber la abundancia que deparará el próximo año. Antes de repartir las tortas, cantarán entre todos el cumpleaños a la Virgen, aplaudirán y tirarán fuegos de artificios.

La manera de festejar el culto implica ciertas inscripciones con las manifestaciones de la cultura popular/carnavalesca bajtiniana: hay formas y rituales de espectáculos eximidos del dogmatismo religioso, todos los devotos "viven" la fiesta y no son simples espectadores, hay un contacto libre y familiar entre los presentes y ese espacio habitado. La fiesta, en este sentido, puede ser comprendida como parte de los rituales que altera el equilibrio de las jerarquías sociales (Da Matta, 2002; Velasco, 1996 y Ortember, 2013), configuración que causa la reproducción de representaciones estigmatizantes sobre el cuerpo de los devotos en la prensa salteña (Nava Le Favi, 2015 y 2016) y una necesidad de disciplinar el culto por parte de la Iglesia.

La fiesta posee aspectos simbólicos y contextuales que resuenan en las prácticas y los discursos de este grupo de familias que sólo pueden ser entendidas si se sitúa a la religiosidad mariana como una forma de occidentalización de los pueblos

\footnotetext{
${ }^{27}$ Las alacitas son elementos materiales que remite a la reproducción en miniatura de bienes inmuebles: casas, autos, certificados de salud, de estudios entre otros. En los festejos, las personas compran las alacitas como un acto simbólico de adquisición de esos bienes que le brindará la Virgen.

${ }^{28}$ Frase de una entrevista realizada a Lía el día 15 de agosto de 2015 durante la fiesta a la Virgen en La Caldera- Salta.

${ }^{29}$ Gavazzo (2006) y Grimson (1999) han dado cuenta de que no existe homogeneidad dentro las colectividades bolivianas, sino una lucha por el prestigio que se manifiestan - por momentos- en los rituales. Este proceso da cuenta que es necesario romper con la mirada de una cultura estática (Herrera, 2000). Más allá que la problemática esbozada no es objeto de este trabajo, se hace necesario mencionar que existen tensiones/disputas por la legitimidad dentro del grupo organizador, las cuales se plasman en prácticas como el manejo del micrófono. Si bien todos pueden usarlo, es la familia Camacho quien se encarga de los equipos y se encuentra durante toda la fiesta al lado del mismo, una puja simbólica que da cuenta de quién tiene - en algún punto- la regulación de la palabra.
} 
Nava Le Favi.“¡Qué viva la mamita!”: territorialidad(es), espesor(es) temporal(es) y resistencias en las prácticas...

americanos que permitieron apropiaciones y disputas de significaciones por parte de los colonizados (Fogelman, 2006). De Certeau también nombra este proceso cuando se pregunta cómo fue el "éxito" de los colonizadores españoles sobre las etnias indias "cómo ésos indios hacían de las acciones rituales, de las representaciones o de las leyes que les eran impuestas algo diferente a lo que el conquistador hacía con ellas" (De Certeau, 1996: 43). Esas "otras" formas fueron amalgamándose, sobre-imprimiendo significados en ritualidades hegemónicas católicas, dando lugar a una heterogeneidad cultural, categoría trabajada por Cornejo Polar (2005) para dar razón de los procesos de producción de literatura pero que posibilita comprender aspectos socio-culturales diversos: el concepto refiere a esa traducción (heteroclítica, quebradiza, múltiple) de un universo cultural a otros. Esa no coincidencia necesaria entre la producción y recepción del enunciado en diversos universos es lo que definiría la heterogeneidad (Cebrelli, 2008) que está presente en ciertas prácticas rituales que reproducen las familias, las cuales están vinculados con "lo andino" "30 que pervive en diversas formas de religiosidad mariana (Canepa Koch, 1998).

Este trabajo se centra en un elemento material y significativo en la construcción de esa territorialidad en relación al espesor temporal y la heterogeneidad cultural: el uso de las "piedras" durante la fiesta, por considerarlo un factor distintivo de sobre-impresión de significaciones en formas de religiosidad mariana. En este sentido, hay estudios que han determinado que las huacas, como lugares sagrados, podían ser cerros, piedras, ríos dedicados a deidades las cuales fueron funcionales para los procesos de occidentalización (Salazar Soler, 1997). En este complejo proceso, la imagen de la Virgen fue fundamental para la colonización(Fogelman, 2006) porque para las etnias indias tenían otra significación: desde la visión andina la forma triangular de las imágenes marianas era similar a los cerros donde habitaban los apus, dioses sagrados (Gisbert $\left.{ }^{31}, 2010\right)$. Esa identificación

\footnotetext{
${ }^{30}$ Hay diferentes discusiones respecto a "lo andino": Kaliman sostiene que "lo andino" pensado como un "inconsciente colectivo" es más una dimensión política que intenta generar una imagen totalizante y está vinculada a una especie de restauración panandina. Otros autores, desde una perspectiva geográfica y que recuperan aportes de la arqueología piensan que existen países Andinos, los cuales serían "Venezuela, Colombia, Ecuador, Bolivia, Perú, Chile y Argentina. Entre estos países se pueden diferenciar los plenamente andinos como Bolivia, Colombia, Ecuador y Perú, de aquellos que poseen un ámbito andino más marginal, tal el caso de Venezuela, Chile y Argentina" (Guerrero, et al 2011). El culto de Urkupiña, como culto boliviano tiene elementos andinos que se entraman en una territorialidad que involucra al NOA. Esto posibilitaría comprender una dimensión más de las apropiaciones que se hacen del culto.

${ }^{31}$ La autora tiene un trabajo interesante que piensa la relación entre la Imagen de la Virgen María, el cerro Potosí y el apu Pachamac, donde por ejemplo, en una pintura de "la Virgen- Cerro" en el museo de La Moneda en Potosí se da cuenta de éste proceso: "En tiempos virreinales fue representada la Virgen María como "madre tierra" en forma explícita; el ejemplo más importante es el cuadro existente en el museo de la Moneda (Potosí) donde María y el Cerro de Potosí son un todo. En el lienzo se muestra la montaña con rostro femenino y un par de manos con las palmas abiertas. Es la imagen de María inserta en el cerro y coronada por la Trinidad. Al pie pueden verse el papa Pablo III, un Cardenal y un Obispo; al lado opuesto, Carlos V y un indígena cuya capa ostenta la cruz de Alcántara, seguramente se trata de un cacique donante. Todos están de hinojos y ante ellos el mundo. En la falda del cerro está el Inca Maita Cápac, el cual según algunos historiadores, es quien conquistó el Collasuyo" (Gisbert, 2010: 177). Esto posibilitaría pensar, cómo la imagen triangular de la Virgen encuentra conexiones con la forma de los cerros (Ibídem).
} 
diferencial a las impuestas por la Institución Católica, posibilita comprender un aspecto más de las condiciones de producción del culto de Urkupiña, devoción colonial boliviana que actualiza diversos elementos andinos en el relato y en las prácticas.

La heterogeneidad se presenta transversalmente a otro proceso de "apropiación" que sigue marcando la manera en la que se configura esa territorialidad: la familia quiere "que (el culto) sea como en Bolivia", ${ }^{2}$ de allí que hayan buscado un lugar geográfico similar al relato de aparición, cerca de un cerro donde puedan extraer las piedras. Éstas son "chayadas" con hoja de coca, papel picado y cerveza. Luego, son quebradas por cada familia para saber cuántos favores recibirán de la "Mamita", es decir, son un indicio de la abundancia y un nexo entre el devoto y su divinidad. La hoja de coca para los pueblos andinos también era una ofrenda para las huacas, junto a piedras, plantas $\mathrm{y}$ animales (Pimentel ${ }^{33}, 2009$ ) que pervivieron en rituales marianos. El uso del alcohol en ceremonias andinas tenía como simbolismo una comunión afectiva y espiritual (Irarrázaval, 1994) lo que amerita a pensar en el espesor temporal de las prácticas que actualizan -en la reproducción de rituales- otros tiempos históricos y, transversalmente, sus prácticas hablan y dicen múltiples territorios que se funden, conviven y disputan.

El uso de alcohol, de fuegos de artificios y las piedras son elementos denostados y no incluidos en las ceremonias que realiza la Institución Católica en Salta a Urkupiña, además que son utilizados por la prensa gráfica para identificar negativamente la práctica del culto (Nava Le Favi, 2015). Allí, podría leerse no sólo la inscripción del discurso religioso (canónico) en los medios, sino también el espesor temporal de una representación católica, dado que desde la edad media el dogma ha buscado suprimir $\mathrm{y}$, posteriormente, "purificar" las fiestas populares por dos cuestiones: una teológica asociada a pensar las prácticas como vestigios paganos $\mathrm{y}$, por el otro, una moral al considerar que son momentos propicios para el pecado (Burke, 1978). El pensamiento racionalista separó la experiencia cuerpo/mente y homologó esa separación entre lo civilizado y primitivo (Miguez, 2002), cavilaciones que perpetúan en la visión católica $\mathrm{y}$ en la concepción de cómo se pueden habitar y decir desde los lugares de poder ésos espacios públicos/privados. La cuestión moral y teológica que impone la Iglesia local se basa en la prohibición/censura en la utilización de elementos constituyentes de las prácticas rituales e incluso en generar acciones como la traslación a una territorialidad aislada del centro de la ciudad para disciplinar el culto: una situación que debe comprenderse en términos que la devoción implica una experiencia que pasa necesariamente por el cuerpo de los devotos y en espacios que se construyen por las agencias como desjerarquizados. Las significaciones otorgadas por los fieles a la cerveza,

\footnotetext{
${ }^{32}$ Frase extraída de una entrevista a Pedro el día 15 de agosto de 2016 durante la fiesta a la Virgen en La Caldera- Salta.

${ }^{33}$ Como lo detalla este autor, debido a que había numerosas deidades, los colonizadores mandaron a identificar y extirpar todas las "idolatrías". Para ello, se elaboraron listados de Huacas, como es la Instrucción para descubrir todas las guacas del Pirú y sus camayos y haziendas, atribuida al párroco Cristóbal de Albornoz, quien la habría escrito a finales del siglo XVI. Este documento, como lo sostendrá Pimentel (2009), es una descripción de los lugares y las ofrendas, entre las cuales se encontraba la hoja de coca.
} 
Nava Le Favi.“¡Qué viva la mamita!”: territorialidad(es), espesor(es) temporal(es) y resistencias en las prácticas...

las piedras, la fiesta son fundamentales para pensar simbólicamente esta territorialidad marcada por diversas memorias, tiempos, relatos e identificaciones.

\section{“¡Gracias, Virgen de Urkupiña!”34: apreciaciones finales y pre-liminares}

La indagación intentó re-construir diversos aspectos contextuales del culto de Urkupiña en la ciudad de Salta: el mapeo se efectuó a partir de la categoría de territorialización para problematizar las dimensiones que adquiere la devoción y su inscripción en el espacio público. En contrapartida, se pensó el proceso de centralización que intenta imponer la Iglesia en Salta y cómo allí el municipio juega un papel importante en la legitimación de los cuerpos que "pueden" habitar el espacio público. Paralelamente, la categoría de territorialidad posibilitó reflexionar sobre las prácticas que realiza el grupo de familias en las que se centró el análisis; los lugares transitables, visibles, habitados y reconocidos por los devotos y las resistencias a aquello que, desde diversos espacios de poder se intenta "institucionalizar", cuadricular, disciplinar e imponer.

Las formas y los lugares para festejar el culto que dispone la Iglesia, no está en los parámetros de lo legítimo de las representaciones y prácticas de este grupo de familias: se presentan grandes diferencias entre las formas de concepción y vivencia del culto. El caso, permite pensar que hay resistencia a lo instituido y, en un complejo proceso, también hay una validación de las prácticas por los devotos que trasciende y se valida por fuera de aquello que el Arzobispo de Salta dispone. Este aspecto está vinculado con el tiempo ellos se adjudican ser los devotos más antiguos de la ciudad y a partir de allí, continúan realizando los rituales que distan de lo "establecido" por la institución. En este sentido, el término de religiosidad popular permite pensar cómo la práctica del grupo constituye una territorialidad atravesada por la negociación y conflicto con lugares de poder.

El análisis es una primera aproximación al caso e intenta ser un aporte al campo religioso mariano salteño y, por lo mismo, ofrece un enclave en términos territoriales/ temporales para reflexionar sobre las identificaciones, las memorias, las prácticas, los discursos, las representaciones de un grupo de familias que "viven"- a su modo- el cumpleaños a la "Mamita".

\section{Referencias Bibliográficas}

Alvarez Leguizamón, S. 2010. “Introducción” en S. Alvarez Leguizamón (comp.) Poder y Salteñidad. Saberes, políticas y representaciones sociales. Salta: CEPHIA, Facultad de Humanidades.

\footnotetext{
${ }^{34}$ El sintagma "Gracias Virgen de Urkupiña" es frecuentemente utilizado en la práctica mariana, la cual se encuentra inscripta (y visible) en los diferentes bienes materiales que los devotos creen que la Virgen posibilitó su adquisición: autos, negocios, entre otros. En este sentido, se constituiría como un índice del proceso de territorialización del culto en la ciudad. Además, durante la fiesta del caso analizado, es una frase que se repite a lo largo del "Cumpleaños a la Mamita".
} 
Ameigeiras, A. 2012. "Ortodoxia doctrinaria y viejas ritualidades. Significados e implicancias en el catolicismo argentino de una aparición mariana”. En: Ameigeiras (coord.) Cruces intersecciones, conflictos. Relaciones politico religiosas en Latinoamérica. Buenos Aires: CLACSO, Colección Grupos de Trabajo.

Angenot, M. 1998. "Hegemonía, disidencia y contradiscurso. Reflexiones sobre la periferia del Discurso Social en 1889” en Interdiscursividades. De hegemonías y disidencias. Córdoba: U.N.C., 29-46; (s/d) "Intertextualidad, interdiscursividad y Discurso Social" Trad. De Cátedra de Nicolás Rosa, Universidad Nacional de Rosario.

Bajtin, M. 1998. La cultura popular en la edad media y en el renacimiento: el contexto de Francois Rabelais. Barcelona, Ed. Alianza.

Bonaparte, J. M. 2005. "La fiesta como espacio de discurso y de prácticas sociales: El caso de la Virgen de Urkupiña en Córdoba", en Migraciones Contemporáneas y Diversidad Cultural en la Argentina. Eduardo E. Domenech (comp.), Centro de Estudios Avanzados, Universidad Nacional de Córdoba.

Bourdieu, P. 2013. El sentido práctico. Buenos Aires: Siglo Veintiuno Editores.

Brubaker, R. y Cooper, F. 2002. "Más allá de identidad”. En: Apuntes de investigación, $\mathrm{N}^{\mathrm{o}} 7$, Buenos Aires.

Burke, P. 1978. La cultura popular en la Europa Moderna. Madrid, Alianza Editorial.

Cebrelli, A y Arancibia, V. 2005. Representaciones sociales. Modos de mirar y de hacer. ( $1^{\mathrm{a}}$ ed.) Salta: CEPIHA-CIUNSa.

Cebrelli, A y Arancibia, V. 2010. “Género, memoria y comunicación. Un abordaje posible al tratamiento de imágenes femeninas en los medios de comunicación” En: Silvia Varg (coord.) Identidades, representaciones, fronteras, género y comunicación. Salta: Municipalidad de Salta, pp. 43-61.

Cebrelli, A y Arancibia, V. 2011. Las representaciones y sus márgenes. (In)visibilidades, imágenes y narrativas en situación de frontera cultural. En: Alberto Constante Director, $\mathrm{N}^{\mathrm{o}}$ 11, Setiembre, Reflexiones Marginales. Revista de saberes de frontera, México, Universidad Autónoma de México.

Cebrelli, A y Arancibia, V. 2012. Luchas y transformaciones sociales en Salta. (1 $\left.{ }^{\mathrm{a}} \mathrm{ed}.\right)$. Salta: Agencia de Ciencia y Técnica y CEPIHA.

Chaile, T. 2010. "Los cultos religiosos en Salta. Procesos de Identidad y relaciones de Poder". Tesis (Doctorado en Historia, Facultad de Humanidades y Ciencias de la Educación) Universidad Nacional de La Plata, La Plata.

Cornejo Polar, A. 1994. Escribir en el aire: Ensayo sobre la heterogeneidad sociocultural de las literaturas andinas. Lima: Horizonte.

Cruz, P. 2009. "Huacas olvidadas y cerros santos. Apuntes metodológicos sobre la cartografía sagrada en los Andes del sur de Bolivia”. En: Estudios Atacameños [en linea]: Disponible en: $<$ http://www.redalyc.org/articulo. oa? id=31516400005> ISSN 0716-0925.

Canepa Koch, G. 1998. Máscara, transformación e identidad en los Andes. La fiesta de la Virgen del Carmen. Perú: Biblioteca Digital Andina.

Charaudeau, P. 2003. El discurso de la información. La construcción del espejo social, Barcelona: Gedisa. 
Nava Le Favi.“¡Qué viva la mamita!”: territorialidad(es), espesor(es) temporal(es) y resistencias en las prácticas...

Da Matta, R. 2002. Carnavales, malandros y héroes. Hacia una sociología del dilema brasileño. México, FCE.

Domenech, E.; Magliano, M. 2007. "Migraciones internacionales y política en Bolivia: pasado y presente”. Estudios Migratorios Latinoamericanos. Número 62. p. 3-42.

Dri, R. 2007. "Símbolos religiosos populares" en R. Dri (comp) Símbolos y fetiches religiosos en la construcción de la identidad popular. Editorial Biblios, Buenos Aires editores, pp. 13-42.

De Certeau, M. 1996. La invención de lo cotidiano. I. El arte de hacer. México: Universidad Iberoamericana.

Deleuze, G. y Guattari, F. 1997. Mil Mesetas. Capitalismo y esquizofrenia. Valencia: Pre-Textos.

Fogelman, P. 2005. "Coordenadas marianas: tiempos y espacios de devoción a la virgen a través de las cofradías porteñas coloniales”. En: trabajos y Comunicaciones, N 30-31.

Flores Klarik, M. 2010. "De la representación del salteño y sus tradiciones a la construcción de los primeros discursos del turismo (1910-1945)". En: S. Álvarez Leguizamón (comp) en Poder y Salteñidad. Saberes, políticas y representaciones sociales. Salta: CEPHIA, Facultad de Humanidades.

Foucault, M. 1983. Beyond, structuralism and heremeneutics. Chicago: University of Chicago Express

Foucault, M .1988.Las redes del poder. Bs. As.: Amalgesto

Foucault, M. 2004. Securite, territorio, population. Cours ou College de France, 19771978, París: Éditions Seuil.

Gavazzo, N. 2006. "Las danzas de Oruro en Buenos Aires: tradición e invención en el campo cultural boliviano", en Cuadernos FHyCS-UNJu, no 31, pp. 79-105.

Grimson, A. 1999. "La Nueva Bolivia y las disputas por la integración. La Fiesta de Nuestra Señora de Copacabana" en Relatos de la diferencia y la igualdad. Los Bolivianos en Buenos Aires. Eudeba, Buenos Aires. Pp. 63-96.

Guerrero, A; Gallucci, S; Michalijos, P. 2011. "Países andinos: Aportes teóricos para un abordaje integrado de las perspectivas geográficas y turísticas”. Revista Huellas $\mathrm{N}^{\circ} 15$ Chile: UPR.

Giorgis, M. 2000. Urkupiña, la virgen migrante fiesta, trabajo y reciprocidad en el boliviano gran Córdoba. Cuadernos Facultad de Humanidades y Ciencias Sociales, Universidad Nacional de Jujuy, No 13, pp. 233-250.

Gisbert, T. 2010. "El cerro de Potosí y el Dios Pachamac”. En: Chungará (Arica), Vol.42, No 1 .

González Sthepan, B. 1995. "Modernización y disciplinamiento. La formación del ciudadano: del espacio público al privado" En: Beatriz González Sthepan, Javier Lasarte, Graciela Montaldo y María Julia Daroqui (comps). Esplendores y miserias del siglo XIX. Cultura y sociedad en América Latina. Caracas, Venezuela: Monte Avila Editores Latinoamericana, pp. 431-457.

Guber, R. 2001. La etnografía, método, campo y reflexividad. Bogotá: Grupo Editorial Norma. 
Guzman, J .2009. "Emergencias religiosas. El caso de la Virgen de Urkupiña” En: Marcelo Lago (dir) Jujuy bajo el signo neoliberal: política, sociedad y cultura en la década de los novena. Jujuy: Ediunju. Pp. 473-501

Hall,S. 2003. “Introducción: ¿quién necesita identidad?”. En: Stuart Hall y Paul Du Gay (comps) Cuestiones de identidad cultural. Buenos Aires: Amorrortu, pp. 13-40.

Hernández, G. 2010. "Relatos de vida y religiosidad popular: origen y sentidos de la fiesta de la Virgen de Urkupiña en Bahía Blanca”. En: Revista Cultura y Religión. Vol. V. No 2, pp. 147-145.

Herrera, N. 2015. "La fiesta como contexto y objeto de investigaciones en el campo de los estudios migratorios en la Argentina” En: XI Reunión de Antropología del Mercosur, Montevideo, Uruguay.

Irarrázaval, D. 1994. Arte de Muerte y Vida e "Inculturación bíblica". En: Un Cristianismo Andino. Quito: Ediciones Abiya Yala, pp. 45-163.

Juarez Bravo, B. 2015.'Devociones reveladas: Performatividad y representación en retratos fotográficos a devotos de la Virgen de Urkupiña en Salta”. En: II Congreso de Comunicación/Ciencias Sociales desde América Latina COMCIS y el I Congreso de Comunicación Popular desde América latina y el Caribe (CCP) organizados por la Facultad de Periodismo y Comunicación Social de la Universidad Nacional de La Plata, Septiembre, 1 - 4 de 2015. La Plata- Argentina. Madrazo, G. 1981. "Comercio interétnico y trueque recíproco equilibrado intraétnico. $\mathrm{Su}$ vigencia en la puna argentina y áreas próximas desde la independencia hasta mediados del siglo XX". En: Desarrollo Económico XXI, N 82.

Marshall, a.; Orlansky, D. 1980. "Las condiciones de expulsión en la determinación del proceso emigratorio desde países limítrofes hacia la Argentina”. En: Desarrollo Económico. Vol. 20. № 80, pp. 491-510.

Martin- Barbero J. 2003. De los medios a las mediaciones. Comunicación, cultura y hegemonía. Bogotá, Convenio Andrés Bello.

Míguez, D. 2002. "Inscripta en la Piel y en el Alma: Cuerpo e Identidad en Profesionales, Pentecostales y Jóvenes Delincuentes”. En: Religiao e Sociedade, 22 (1) pp. 21-57.

Nava Le Favi, D. 2016. “Territorialidades y espacio público. El caso de los devotos al culto del Milagro y Urkupiña en Salta”. En: VI Jornadas del Norte Argentino de Estudios Literarios y Lingüísticos. Territorios de la Memoria. Realizado en la Universidad Nacional de Jujuy 15-16 de septiembre, 2016. San Salvador de Jujuy- Argentina.

Nava Le Favi, D. 2015. "Nos han invadido las pulgas": narrativas e identidad(es) entorno al promesante de la Virgen de Urkupiña en Salta" En: VIII Seminario regional ALAIC (cono sur) "Políticas, actores y prácticas de la comunicación. Encrucijadas de la investigación en América Latina" Escuela de Ciencias de la Información, Universidad Nacional de Córdoba 27-28 de agosto, 2015. Córdoba- Argentina.

Nava Le Favi, D .2013. La construcción del imaginario salteño respecto al culto de la Virgen del Milagro y la Virgen del Cerro en Salta. Identidades, actores sociales, conexiones y aristas de dos hechos religiosos locales. Tesis (Licenciatura en Ciencias de la Comunicación). Salta, Argentina. Universidad Nacional de Salta, Facultad de Humanidades. 
Nava Le Favi.“¡Qué viva la mamita!”: territorialidad(es), espesor(es) temporal(es) y resistencias en las prácticas...

Ortember P. 2013. "Sentidos e historia de las fiestas patrias: una introducción”. En: P. Ortember (comp) El origen de las fiestas patrias: Hispanoamérica en la era de las independencias. Protohistoria Ediciones, Rosario, Argentina, pp. 11-27.

Passarelli A., y Giménez, J. 2015. "Rupturas y continuidades entre Copacabana y Urkupiña. Aproximaciones a los sentidos de dos festividades bolivianas en La Plata". En: Question, Vol. 1, No 45, enero-marzo.

Petracci, M. 2004. "La agenda de la opinión pública a través de la discusión grupal. Una técnica de investigación cualitativa: el grupo focal". En: Kornblit (coord) Metodologías Cualitativas en Ciencias Sociales: Modelos y Procedimientos de Análisis. Bs. As: Ed. Biblos, pp. 77-89.

Pimentel, G. 2009. Las huacas del tráfico. Arquitectura ceremonial en rutas prehispánicas del Desierto de Atacama. En: Boletín del Museo Chileno de Arte Precolombino [En línea], Vol. 14, $\mathrm{N}^{\circ}$ 2. Consultado el 4 de Abril de 2017. URL: http://www. scielo.cl/pdf/bmchap/v14n2/art02.pdf

Reguillo, R. 2008. 'Políticas de la (In)visibilidad. La construcción social de la diferencia' Clase $\mathrm{N}^{\mathrm{o}} 5$ del Curso Educación, Imágenes y Medios, Buenos Aires, FLACSO.

Rivero Sierra, F. 2008. Los bolivianos en Tucumán. Migración, cultura e identidad. San Miguel de Tucumán: Consejo de investigaciones- Universidad Nacional de Tucumán. Rodríguez, M. G. 2008. "La pisada, la huella y el pie". En: Alabarces, P. y M. G. Rodríguez (comp) Resistencia y mediaciones. Estudios sobre cultura popular. Bs. As.: Paidós, pp. 307-335.

Rodríguez, M. G. 2011. "Las representaciones y sus márgenes. Identidades y territorios en situación de frontera". En: Reflexiones Marginales $\mathrm{N}^{\circ} 10$, México: UNAM.

Segato, R. 2008. "La faccionalización de la república y el paisaje religioso como índice de una nueva territorialidad". En: América Latina y el Caribe. Territorios religiosos y desafíos para el diálogo. Aurelio Alonso (Compilador). CLACSO, Consejo Latinoamericano de Ciencias Sociales, Buenos Aires.

Segato, R. 2007. La nación y sus otros. Raza, etnicidad y diversidad religiosa en tiempos de políticas de identidad. Bs. As.: Prometeo.

Serafino, M.A. 2010. La celebración de una virgen migrante, construcciones identitarias entre bolivianos y santafesinos en un sector de Quintas al norte de la ciudad de Santa Fe, Argentina. Sociedad Económica, Nº19, pp.117-134.

Semán, P. 2000. "El Pentecostalismo y la religiosidad de los sectores populares" en M. Svampa (comp) Desde Abajo: la transformación de las identidades sociales. Universidad Nacional de General Sarmiento-Editorial Biblos, Buenos Aires, pp. 155-180.

Turner, V. 1969. El proceso ritual. Taurus, Madrid.

Yudi, R. 2015. Kollas de nuevo: Etnicidades, trabajo y clasificaciones sociales en los Andes, Argentina. San Salvador de Jujuy: Purmamarka ediciones.

Velasco, H. 1986. "Rituales e identidad: dos teorías y algunas paradojas". En: Revista de Occidente, $\mathrm{N}^{\mathrm{o}} 56$, enero, pp. 65-75.

Verón, E.1987. La semiosis social. Fragmentos de una teoría de la discursividad. Barcelona: Gedisa. 